\title{
The Influence of Ostomy Closure Opportunity Choice on the Prognosis of the infants with Necrotizing Enterocolitis
}

\author{
Ji-xue Zhao ${ }^{1, a}$, Xin $\mathrm{Fu}^{2, \mathrm{~b}}$
}

${ }^{1}$ Department of Pediatric Surgery, The First Hospital of Jilin University, Changchun 130021, China;

${ }^{2}$ Nursing Administration Department, China-Japan Union Hospital of Jilin University, Changchun 130033, China

E-mail: $\frac{\text { aixuezhao0431@126.com, }{ }^{b} \text { xinfu0431@126.com }}{{ }^{b} \text { corresponding author }}$

\section{Keywords: Necrotizing enterocolitis, ileostomy, ostomy closure}

Abstract. Objective: To explore the the influence of different ostomy closure opportunity choice on the prognosis of the patient with necrotizing enterocolitis (NEC). Methods: From January 2012 to January 2018, 36 infants with NEC which had been performed ileostomy were treated with different ostomy closure opportunity choice in the First hospital of Jilin University. These infants were divided into three groups randomly: Early ostomy closure group: 12 patients were performed early ostomy closure(less 3 months after ostomy), normal ostomy closure group : 14 patients were performed normal ostomy closure(3-6 months after ostomy), late ostomy closure group: 10 patients were performed early ostomy closure(more 6 months after ostomy), clinical data were retrospectively analyzed, including the time from ostomy to ostomy closure, the mean operation time, the intraoperative bleeding, the averaged length of stay (ALS), the incidence of postoperative wound infections. Results: The time from ostomy to ostomy closure of three groups was different $(\mathrm{P}<0.05)$. There were no significant difference in the mean operation time among the three groups $(\mathrm{P}>0.05)$. The difference of the operative blood loss in three groups were not statistically significant $(\mathrm{P}>0.05)$. The difference of the averaged length of stay (ALS) in three groups were not statistically significant $(\mathrm{P}>0.05)$, and the incidence of postoperative wound infections were not different among the three groups too( $P>0.05)$. Conclusions: The early ostomy closure did not have the negative effect for the infants with NEC. Compared with normal ostomy closure and late ostomy closure, early ostomy closure could restore the bowel function earlier, and could avoid Long-term dehydration and malnutrition during the waiting for ostomy closure.

\section{Introduction}

Necrotizing enterocolitis (NEC) is an acute and potentially fatal disease characterized by inflammation and necrosis in the gastrointestinal tract. Incidence of NEC is between 7\% and $12 \%$ in preterm very low birth weight infants with an estimated mortality of 15\%-30\% [1]. The pathogenesis of NEC is still incompletely understood, but it is thought that several factors are involved interactively, such as premature birth, low birth weight, ischemia/reperfusion injury, abnormal gut bacterial colonization, and inappropriate enteral feeding [2].

Many NEC cases which have no intestinal necrosis and perforation can get conservative treatment during early stage, and many of them could get successful treatment.But the data show that $20 \%-60 \%$ of the children still need the surgery[3]. NEC can affects the small intestine and colon, but the predilection site is in the distal ileum and ascending colon proximal. So the operation of NEC always include the resection of necrotic bowel and ostomy of the distal ileum, and 3-6 months after the ostomy, ostomy closure will be performed. Because of the loss of fluid and electrolytes and nutrition malabsorption after the ostomy[4], many children always get severe malnutrition, and need intermittent parenteral nutrition to support the life. Even many of them need hospitalization to correct dehydration and malnutrition, which will increase the children's suffering and burden of the parents. If we can perform the early ostomy closure which will restore the intestinal function has become our main research topic. Based on these considerations above, From January of 2012, we try the different timing of ostomy closure, in order to find the best ostomy closure opportunity. 


\section{Patients and methods}

\section{Patients}

From January of 2012 to January of 2018, 36 infants with NEC which had been performed ileostomy in the neonatology department, the First Hospital of Jilin University were enrolled in this retrospective analysis. Each patient signed an informed consent form. Approval was obtained from the institutional review committee of Jilin University.

\section{Study Design}

These infants were divided into three groups randomly: Early ostomy closure group: 12 patients were performed early ostomy closure(less 3 months after ostomy), normal ostomy closure group : 14 patients were performed normal ostomy closure(3-6 months after ostomy), late ostomy closure group: 10 patients were performed early ostomy closure(more 6 months after ostomy).

Normal and late ostomy closure: According to the traditional methods, we can perform the ostomy closure 3-6 months after the first operation.

Early ostomy closure : We can perform the the ostomy closure less 3 months after ostomy. During two weeks before the ostomy closure, we should treat the patients with intravenous hyperlimentation and proper enteral nutrition to correct dehydration, ion disorder and malnutrition. And when the general condition improved, we can perform ostomy closure timely.

\section{Evaluation Criteria of Treatment Effects}

Evaluation criteria included the time from ostomy to ostomy closure, the intraoperative bleeding, the mean operation time, the averaged length of stay (ALS), the incidence of postoperative wound infections.

\section{Statistical Analysis}

All measured parameters including the time from ostomy to ostomy closure, the mean operation time, the operative blood loss, the averaged length of stay (ALS), were analyzed by the statistical software program Statistical Product and Service Solutions (SPSS) 17.0 (SPSS Inc., Chicago, IL, USA) and expressed as mean \pm standard deviation $( \pm \mathrm{s})$, and t-test was used. Enumeration data including gender, prevalence frequency were analyzed by $\chi 2$ test. $\mathrm{P}<0.05$ was considered significant.

\section{Results}

\section{Baseline Characteristics}

There were no significant difference $(\mathrm{P}>0.05)$ in general data including operation age, gender among the three groups (Table 1.).

Table 1. Baseline characteristics of study patients

\begin{tabular}{lccc}
\hline & Female / Male & $\begin{array}{c}\text { First operation age } \\
\text { (days) }\end{array}$ & $\begin{array}{c}\text { First operation neonatal } \\
\text { weight(kg) }\end{array}$ \\
\hline $\begin{array}{l}\text { Early ostomy closure } \\
\text { group }\end{array}$ & $4 / 8$ & $9.1 \pm 2.9$ & $2.6 \pm 0.7$ \\
$\begin{array}{l}\text { Normal ostomy } \\
\text { closure group }\end{array}$ & $5 / 9$ & $8.8 \pm 3.1$ & $2.4 \pm 0.9$ \\
$\begin{array}{l}\text { Late ostomy closure } \\
\text { group }\end{array}$ & $3 / 7$ & $8.9 \pm 2.9$ & $2.5 \pm 0.8$ \\
P>0.05, compared among the three groups. & &
\end{tabular}

\section{Evaluation of Treatment Effects}

All affected infants have undergone ostomy closure successfully and have recovered satisfactorily. No dead case was found during the hospitalization.

The time from ostomy to ostomy closure, mean operation time, the operative blood loss, the averaged length of stay (ALS), the incidence of postoperative wound infections after operation were analyzed. The time from ostomy to ostomy closure of experimental group was obviously less than that 
of control group $(\mathrm{P}<0.05)$. There were no significant difference in the mean operation time between the two groups $(\mathrm{P}>0.05)$. The difference of the operative blood loss in two groups were not statistically significant $(\mathrm{P}>0.05)$. The difference of the averaged length of stay (ALS) in two groups were not statistically significant $(\mathrm{P}>0.05)$. There were no significant difference in the incidence of postoperative wound infections between the two groups $(\mathrm{P}>0.05)$, as is shown in Table 2 . Postoperative follow-up was conducted for 3-6 months.

Table 2 Efficacy of the three groups

\begin{tabular}{|c|c|c|c|c|c|c|}
\hline & $\begin{array}{l}\text { Number } \\
\text { of cases }\end{array}$ & $\begin{array}{l}\text { Ostomy closure } \\
\text { time (months) }\end{array}$ & $\begin{array}{c}\text { Mean } \\
\text { operation } \\
\text { time(minutes) }\end{array}$ & $\begin{array}{l}\text { Blood loss } \\
\quad(\mathrm{ml})\end{array}$ & $\begin{array}{l}\text { The averaged } \\
\text { LOS *(days) }\end{array}$ & $\begin{array}{l}\text { Infection } \\
\text { incident }\end{array}$ \\
\hline $\begin{array}{l}\text { Early ostomy } \\
\text { closure group }\end{array}$ & 12 & $1.66 \pm 0.78$ & $63.4 \pm 9.5 \#$ & $6.1 \pm 1.7 \#$ & $7.7 \pm 1.4 \#$ & 2/12 \# \\
\hline $\begin{array}{l}\text { Normal ostomy } \\
\text { closure group }\end{array}$ & 14 & $4.52 \pm 1.44 *$ & $61.5 \pm 11.1 \#$ & $5.9 \pm 1.2 \#$ & $7.4 \pm 1.3 \#$ & $3 / 14$ \# \\
\hline $\begin{array}{l}\text { Late ostomy } \\
\text { closure group }\end{array}$ & 10 & $7.44 \pm 1.23 * \triangle$ & $63.9 \pm 10.8 \#$ & $5.8 \pm 1.6 \#$ & $7.5 \pm 1.8 \#$ & $1 / 10 \#$ \\
\hline
\end{tabular}

\section{Discussion}

Necrotizing enterocolitis(NEC) is an inflammatory intestinal disorder primarily seen in premature infants, characterized by variable damage to the intestinal tract, ranging from mucosal injury to full-thickness necrosis and perforation. NEC belongs to the acquired intestinal inflammatory diseases, and it is more common in premature and low birthweight. NEC can cause severe multiple organ and systemic inflammation reaction, and always lead to the mortality rate of 20\%-30\%[5-7]. The survivor always accompanied enterostenosis(15\%-30\%), short bowel syndrome and cholestatic liver diseases, and so on[8]. NEC is very hard to treat, and most of the infants with NEC need surgery, and the early surgery is safe and effective[9].

NEC can affects the whole small intestine and colon, but the predilection site is in the distal ileum and ascending colon proximal. So the operation of NEC always include the resection of necrotic bowel and ostomy of the distal ileum, and after 3-6 months, ostomy closure will be performed. Because the necrotic bowel loops has been removed, the left loops have become very short(always less than $100 \mathrm{~cm}$ and even only left $40-50 \mathrm{~cm}$ ), which will obviously decrease the nutrition absorption, and lead to severe malnutrition. Additionally, ileostomy cause that the water cannot be absorbed by colon, which will lead to the great loss of fluid and electrolyte. Many of the patients suffered from frequent diarrhea and subsequent severe dehydration. Longstanding dehydration and malnutrition can lead to the difficult recovery, which can cause that the infants cannot tolerate the surgery, and even can endanger their lives. Most of the patients always need intermittent parenteral nutrition to support the life. While the long time parenteral nutrition can lead to many complications such as liver damage, this will set up a circle of aggravating. Many patients need the repeated hospitalization to correct the severe dehydration and malnutrition, which can increase not only the patients'suffering, but also the economic burden of parents. Therefore, we positively discuss the possibility of early ostomy closure.

At present, most of the doctors always perform the ostomy closure 3-6 months after the ostomy. Through the retrospective analysis, Struijs MC pointed out, this systematic review showed that complication rate did not differ between early and late closure of ostomy in patients with necrotising enterocolitis[10].

According to the above analysis, we try the different timing of ostomy closure(less 3 months, 3-6 monthes, more 6 months), in order to find the best ostomy closure opportunity. From the retrospective analysis of the clinical data, we can find that there were no significant difference in the mean operation time among the three groups. The difference of the operative blood loss in three groups were not statistically significant. The difference of the averaged length of stay (ALS) in three groups were not statistically significant and the incidence of postoperative wound infections were not 
different among the three groups too. And those indicate that early ostomy closure did not have a negative effect for the infants. While the early ostomy closure can recover the gut function early, avoid the dilemma of long time dehydration and malnutrition during the waiting for ostomy closure, and the advantages are obvious. So we think that early ostomy closure is clinically feasible.

In our experience, as for the early ostomy closure, the most important of all is to assess and restore the nutrition state of the infants with NEC before the ostomy closure. During two weeks before the ostomy closure, according to the different condition of the different patients, including the weight, the age, the degree of dehydration and malnutrition, and so on, we should treat the patients with intravenous hyperlimentation and proper enteral nutrition to correct dehydration, ion disorder and malnutrition. And when the general condition improved, we can perform ostomy closure timely.

In conclusion, currently no final conclusion has yet been reached on the time from ostomy to ostomy closure. The recognized time is 3-6 months after the ostomy. Under the condition of ensuring the safety of patients, we reduce the waiting time properly in accordance with specific conditions, and achieved a good clinical effect.

\section{Conclusion}

The early ostomy closure did not have the negative effect for the infants with NEC and it could restore the bowel function earlier, avoid long-term dehydration and malnutrition during the waiting for the ostomy closure. And the early ostomy closure is clinically feasible for the infants with NEC which had been performed ileostomy.

\section{References}

[1] Neu, J.; Walker, W.A. Necrotizing enterocolitis. N. Engl. J. Med. 2011, 364, 255-264.

[2] Chen, A.C.; Chung, M.Y.; Chang, J.H.; Lin, H.C. Pathogenesis implication for necrotizing enterocolitis prevention in preterm very-low-birth-weight infants. J. Pediatr. Gastroenterol. Nutr.2014, 58, 7-11.

[3] Thompson AM, Bizzarro MJ. Necrotizing enterocolitis in newborns:pathogenesis, prevention and management. Drugs. 2008;68(9):1227-1238.

[4] Steinau G, Ruhl KM, Hörnchen H, et al. Enterostomy complications in infancy and childhood[J]. Langenbecks Arch Surg, 2001, 386(5) : 346-349.

[5] Thompson A, Bizzarro M, Yu S, et al. Risk factors for necrotizing enterocolitis totalis: a case-control study [J]. J Perinatol, 2011,31 (11): 730-738.

[6] Gephart SM, McGrath JM, Effken JA, et al. Necrotizing enterocolitis risk: state of the science[J]. Adv Neonatal Care, 2012, 12 (2) : 77-87.

[7] Diehl Jones ML, Askin DF, Nutritional modulation of neonatal outcome[J],AACN Clinical Issues, 2004,15(1):83-96.

[8] Neu J, Chen M, Beierle E. Intestinal innate immunity: how does it relate to the pathogenesis of necrotizing genterocolitis[J]. Semin Pediatr Surg, 2005,14(3):137-144.

[9] Gfroerer S, Fiegel H, Schloesser RL,et al. Primary laparotomy is effective and safe in the treatment of necrotizing enterocolitis[J]. World J Surg. 2014, 38(10):2730-2734.

[10] Struijs MC, Sloots CE, Hop WC, et al. The timing of ostomy closure in infants with necrotizing enterocolitis: a systematic review[J]. Pediatr Surg Int. 2012 Jul;28(7):667-672. 